\title{
THE CONTROL SYSTEM FOR THE MULTIPLE-PELLET INJECTOR ON THE JOINT EUROPEAN TORUS
}

\author{
L. R. Baylor, T. C. Jernigan, and K. A. Stewart \\ Oak Ridge National Laboratory, * Oak Ridge, Tennegsee 37831-8071
}

\section{ABSTRACT}

A stand-alone control and data acquisition system for the Oak Ridge National Laboratory (ORNL) multiplepellet injector installed on the Joint European Torus (JET) has been desisned and installed with the injector. This system, which is based on a MicroVAX II computer and a programmable logic controller (PLC), is an upgrade of previous systems designed for ORNL pellet injectors installed on other fusion experiments. The primary control system upgrades are in the user interface, in the automation of sequential irijector operation, and in the analysis of the transient data acquired for each pellet fired. The system is integrated into the JET CODAS environment through CAMAC communications modules with customized coinmunications softrare. Routine operation of the injector is automated and requires no operator iniervention. Details of the hardware and software design and the operation of the system are presented in this paper.

\section{INTRODUCTION}

A control and data acquisition system has been designed at ORNL for use with a three-bartel repeating pneumatic pellet injector that was built at ORNL and installed on JET [1]. This system is an upgraded version of the control system that was developed for the repeating pneumativ injector (RPI) and the deuterium pellet injector (DPI) that were installed on the Tokamak Fusion Test Reactor (TFTR) [2]. The control system is an independent stand-alone system that requires no interfaces to the JET supervisory COntrol and Data Acquisition System (CODAS) in order to operate the injector. This stand-alone feature made it possible to fully commission the system before shipment to and installation on JET; it also makes it possible to operate the injector in a test mode at JET with minimal CODAS intervention. The system provides for all the control functions needed by the injector and also has transient digitizers to collect data from pellet diagnostics for every pellet fired.

\section{HARDWARE CONFIGURATION}

The system is based on a MicroVAX II computer that communicates with an Allen-Bradley model 2/30 PLC, which performs all of the control functions except the actual firing of the gans. The firing triggers for the guns are provided by a JET-supplied, CAMAC-based timed triggering system called a fire sequencer that is initiated by a start of pulse trigger from the JET central timing system. Figure 1 is a block diagram of the control and data acquisition system. Two identical operator control stations are provided with color mimic displays driven by a CAMAC display module and an alphanumeric terminal with graphics capability. One operator station is in the JET machine control room, and the other is located in a diagnostic wing closer to the injector controls. $A$ set of five instrumentation racks, which hold the PLC, fast valve power supplies, temperature controllers, and diagnostic instrumentation, is located in the JET basement below the injector. To simplify installation, five large multiconductor cables are run between a junction box next to the injector and a junction box on the instrumentation racks in the basernent. All of the individual signal cables break out of the junction boxes to their respective instruments or sensors. The CAMAC byte serial highway is run from the MicroVAX CAMAC highway driver in the control room to the operator stations and to the basement instrumentation racks via fiber-optic U-port adapters.

Nine independent cryogenic temperature controllers with IEEE-488 interfaces are used to control the temperatures of each of the guns in the injector. A CAMAC IEEE-488 module is used to allow the MicroVAX to communicate with each of the temperature controllers to read the temperatures and change the setpoints. Analog outputs of the temperature controllers are used to interlock the extruder motion.

The data acquisition hardware congists of a set of $50-\mathrm{kHz}$ and $1-\mathrm{MHz}$ digitizers for each of the three guns in the injector. These digitizers are used to acquire two signals of slow injector diagnostics and one signal of fast pellet diagnostics for each pellet. The digitizers are clocked on by the fire sequencer only during the actua! firing of

*Oak Ridge National Laboratory is operated by Martin Marietta Energy Systems, Inc., under contract DE-AC0584OR21400 with the U.S. Department of Energy. 


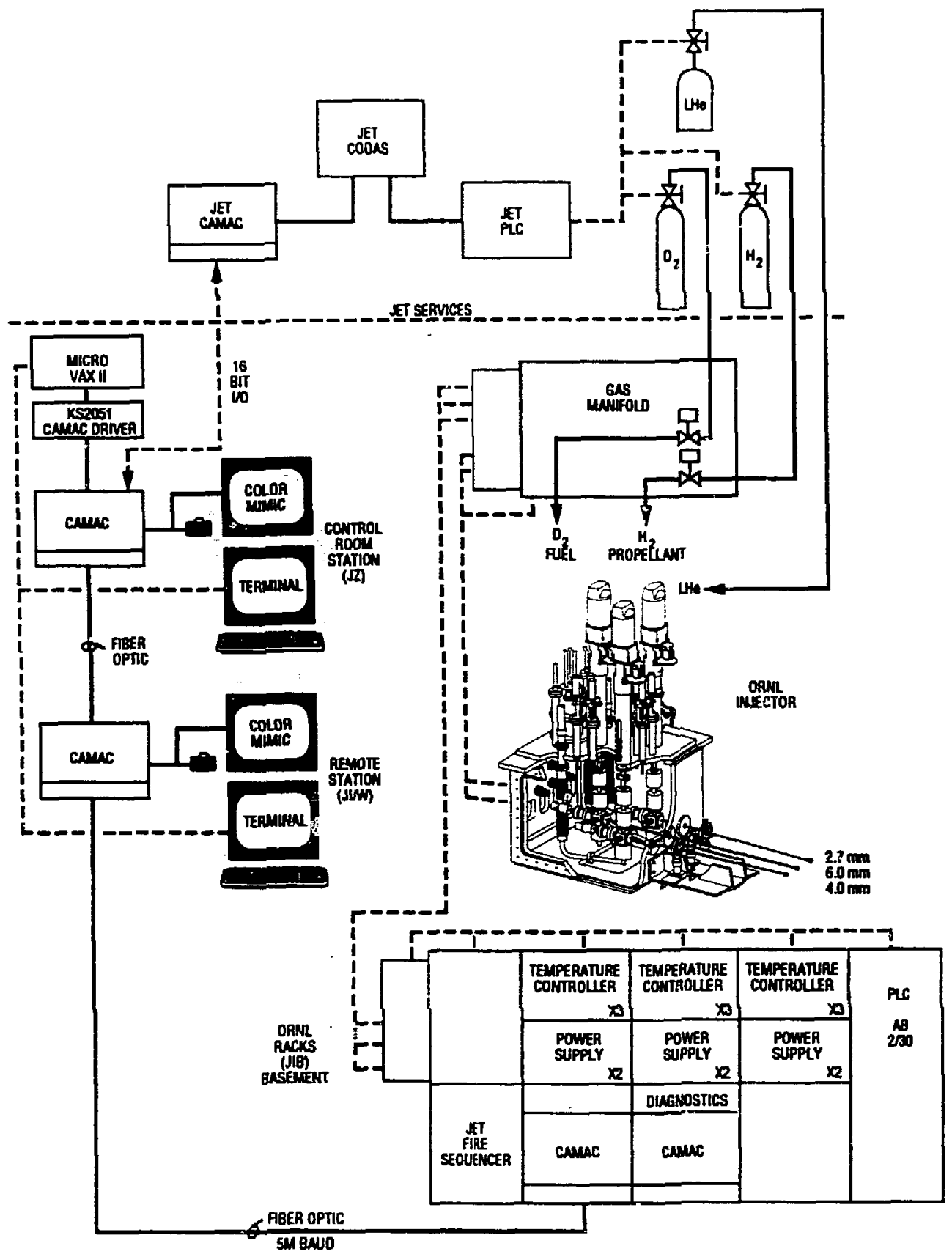

Fig. 1. Diagram of the pellet injector control system as installed at JET.

the pellet, thus enabling the multiplexing of up to 32 pellets in each digitizer channel.

\section{INTERFACE TO JET CODAS}

A communications link was installed between the MicroVAX and one of the JET CODAS computers to transfer the transient pellet data from the MicroVAX and to issue pulse numbers and commands from the JET CODAS system. This link is based on CAMAC 16-bit parallel $\mathrm{I} / \mathrm{O}$ modules that reside in crates on both the MicroVAX and CODAS computer CAMAC highways and uses a custom-designed software protocol. In this communications link, the CODAS computer is the master and initiates all data transactions. 
An RS-232 serial link was established between the injector PLC and the JET pellet services PLC to relay the status of the JET services subsystem (i.e., vacul $m$, liquid helium, and gas supply). The injector PLC also requests the JET pellet services PLC to enable the operation of the individual guns via this link. If the JET pellet services subsystem is available, then the individual guns are enabled upon request and may then be fired.

\section{SOF'TWARE DESIGN}

The PLC program is written in ladder logic and is designed around a finite state engine. There are four states that the PLC can be in: OPERATE, STANDBY, FIRE, and TEST. Only the FIRE state has a programmed sequence of injector operations; interlocks for the various control elements vary from state to state. Commands to operate the control elements and change state are initiated from the MicroVAX and are performed by the PLC if permitted in the current state. The PLC program also contains sections that are state independent, such as communications with the MicroVAX and the reading of analog input signals.

The MicroVAX system is based on a number of detached processes, each of which handles a particular aspect of the injector control and data acquisition system. A diagram of these processes and their interactions is shown in Fig. 2. Separate processes exist for handling the communications with the PLC (PLC), with the temperature controllers (TEMPS), with the fire sequencer (SEQ), and with the CODAS link (CODAS). There is also a process for driving the mimic displays (MIMIC), one for monitoring the trackball used with the mimic displays (CONTROL), one for periodically archiving injector status data (TREND), and one for handling the data acquisition from transient digitizers (ADC).

A separate detached process called AUTO also exists to read automatic procedures written in a pseudoFORTRAN interpreted language and perform the requested operations. Execution of these automatic procedures can be initiated interactively or from commands through the CODAS communications link. As the automatic procedure is interpreted, the appropriate commands are sent to the PLC, temperature controllers, or fire sequencer to accomplish the requested action. The AUTO interpreter has the capability of handling such control statements as DO loops, IF-THEN-ELSE constructs, and WAIT statements.

Three global sections (shared memory) are used by the MicroVAX processes to share injector status data, control setpoints, and pellet diagnostic data. Common event flags are used between the processes to signal the beginning and end of pulses. Mailbox memory is used to transfer the screen location of the mimic cursor between the mimic process and the control process. All of the de- tached processes log error messages to a common log file, and an alarm condition within any process is indicated on the mimic displays.

An interactive program called MENU is run on a terminal to allow the operator to view and modify all of the system setpoints and pellet firing times. This program uses the Forms Management System (FMS) package and has eight different forms for entering data. One form is dedicated for initiating automatic procedures and monitoring their progress as they run. All of the software on the MicroVAX is built and maintained using the Module Management System (MMS) package.

\section{OPERATION OF THE SYSTEM}

The system is highly automated by the AUTO process, which runs procedures to accomplish tasks such as cooling one or more of the guns down, preparing the guns for a pulse, and shutting the guns down after operation. These procedures can be initiated from operator commands through the MENU program or by commands received through the CODAS communications link. The automation of the routine injector operation has contributed to a high level of injector reliability [3].

Typically, shift technicians use the CODAS interface with the MicroVAX to initiate the automatic procedure for cooldown of the guns. The pellet injector operator initiates a plugging procedure after the guns are cold to form the extrusion of solid deuterium in the guns. When the injector is ready for pellet injection, the CODAS system initiates the start of a preshot automatic procedure on the MicroVAX at $\mathbf{3 0}$ seconds before the start of the discharge (pulse). This preshot procedure then extrudes solid deuterium for the pellets in the guns that are being used and puts the PLC into its STANDBY state. When the fire sequencer has begun its countdown, it signals to the PLC to change to the FIRE state, where the PLC then runs the extruders during the firing of pellets. When the pulse is complete, the preshot procedure pulls the extruders back out and puts the PLC back into the OPERATE state. The ADC process reads the data when it is notified by an event flag from the CODAS communications process that the pulse is completed. Once the data are read into shared memory, they are stored to a disk file in compressed format and sent in compressed format by the CODAS communications process to the JET CODAS computer. From there, the data are trangferred to the JET IBM mainframe. There are typically 3-5 kbyte of diagnostic data for each pellet that is fired.

An interactive program called PELPLOT has been developed to plot and analyze the pellet diagnostic data and trend data acquired. PELPLOT is run automatically by a command procedure after every pulse and generates a summary plot of the diagnostic data for each 


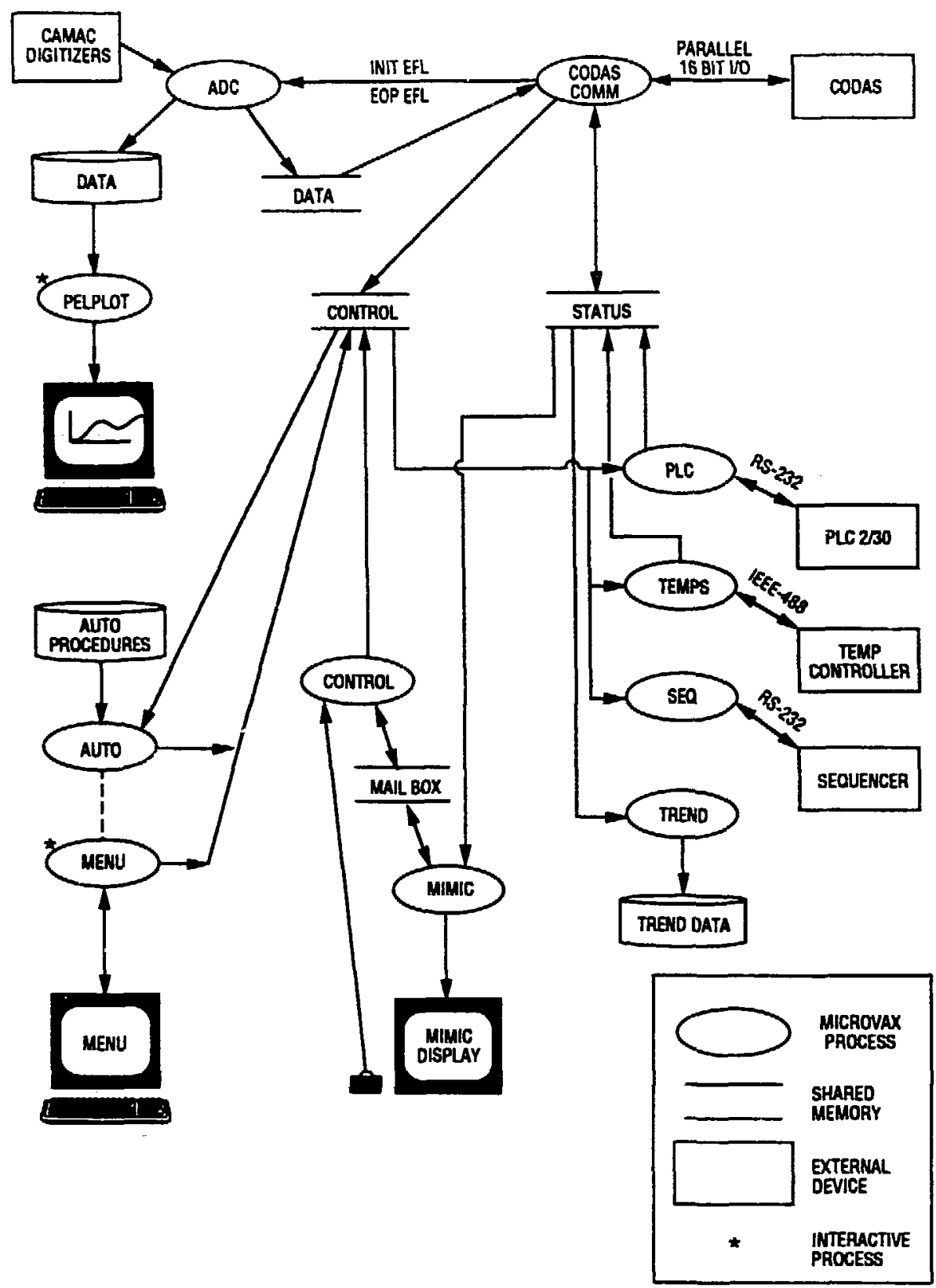

Fig. 2. Block diagram of the software interaction on the MicroVAX.

pellet. PELPLOT' also calculates the pellet mass, pellet speed, and penetration distance into the plasma from the pellet diagnostic signals [4] and displays the values on the summary plot, as shown in the example in Fig. 3.

\section{ACKNOWLEDGMENTS}

The authors acknowledge the efforts of the JET CODAS staff, who specified the interfaces to the CODAS 

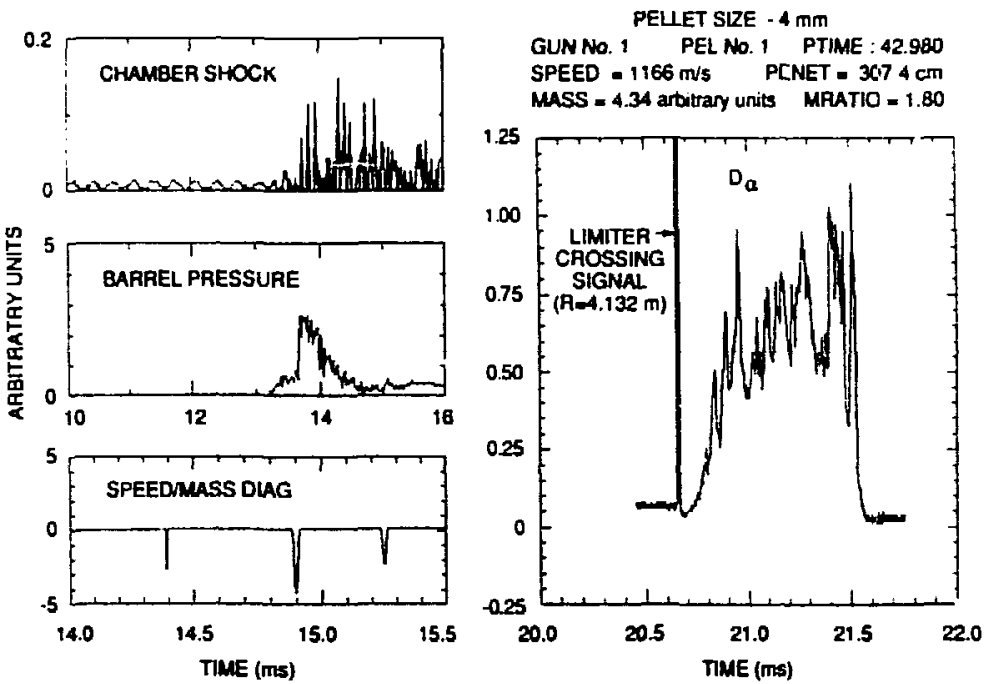

Fig. 3. Data for a typical pellet from the pellet data acquisition sequerce.

environment, and of the JET pellet fueling team, who assisted in the installation and operation of the system. The contribations of S. Combs, S. Milora, R. Shanlever, D. Sparks, and R. Overbey of ORNL are greatly appreciated. This work was performed under the pellet fueling collaboration between the JET Joint Undertaking and the U.S. Department of Energy.

\section{REFERENCES}

[1] S. L. Milora et al., "The JET multipellet launcher and fueling of JET plasmas by multipellet injection," in Proceedings of the 15 th European Conference on
Controlled Fusion and Plasma Physics, 1988, Part I, p. 147.

[2] L. R. Baylor et al., "Design and implementation of a control and data acquisition system for pellet injectors," in Proceedings of the 11th Symposium on Fusion Engineering, 1986, vol. 1, p. 602.

[3] S. K. Combs et al., "Operation and reliability of a pneumatic hydrogen pellet injection system on the Joint European Torus," these proceedings.

[4] W. Bailey et al., "Diagnostics for the JET multipellet injector," in Fusion Technology 1988: Proceedings of the 15th Symposium, 1988, vol. 1, p. 720.

\section{DISCLAIMER}

This report was prepared as an account of work sponsored by an agency of the United States Government. Neither the United States Government nor any agency thereof, nor any of their employees, makes any warranty, express or implied, or assumes any legal liability or responsibility for the accuracy, completeness, or usefulness of any info:mation, apparatus, product, or process disclosed, or represents that its use would rial infringe privately owned rights. Reference herein to any specific commercial product, process, or service by trade name, trademark, manufacturer. or otherwise does not necessarily constitute or imply its endorsement, recommendation, or favoring by the United States Government or any agency thereof. The views and opinions of authors expressed herein do not necessarily state or reflect those of the United States Government or any agency thereof. 